\title{
Modos de herencia de la morfología dental en familias Misak del municipio de Silvia (Cauca, Colombia)
}

research paper

\section{Inheritance modes of dental morphology in Misak families of the municipality of Silvia (Cauca, Colombia)}

\section{Lizeth Hurtado 1}

Universidad del Valle. Colombia

(i) https://orcid.org/0000-0001-8023-295X

\section{Linda Montenegro 2}

Universidad del Valle. Colombia

(i) https://orcid.org/0000-0002-8371-0360

\section{Cindy Pardo ${ }^{3}$}

Universidad del Valle. Colombia

(iD https://orcid.org/0000-0003-2102-3108

\section{Mónica Tipas 4 \\ Universidad del Valle. Colombia \\ (D) https://orcid.org/0000-0002-6305-3383}

\author{
Andrés Zuleta ${ }^{5}$ \\ Pontificia Universidad Javeriana Cali \\ (i) https://orcid.org/0000-0002-8275-1144
}

\author{
Sandra Moreno 6 \\ Pontificia Universidad Javeriana Cali \\ Universidad del Valle. Colombia \\ (iD) https://orcid.org/0000-0003-1435-614X
}

\author{
Freddy Moreno ${ }^{7}$ \\ Pontificia Universidad Javeriana Cali \\ Universidad del Valle. Colombia \\ (iD) https://orcid.org/0000-0003-0394-9417
}

Resumen: Este es un estudio descriptivo transversal cuantitativo que identificó el modo de herencia de 14 Rasgos Morfológicos Dentales (RMDC) a partir de la frecuencia, la variablidad, el dimorfismo sexual, la asimetría bilateral y la correspondencia entre rasgos, en modelos de yeso obtenidos de un grupo de diez familias - madre, padre e hijo(a) - que forman parte de la comunidad misak del municipio de Silvia (Cauca, Colombia). Se emplearon los sistemas de registro para dentición decidua Arizona State University Dental Anthropology System (ASUDAS, 1991) para crowding, winging y cúspide 6, Grine (1986) para cúspide de Carabelli, Sciuli (1998) para protostílido, pliegue acodado, patrón cuspídeo y número de cúspides, y Hanihara (1966) para cúspide 7; y para dentición permanente ASUDAS para los 14 RMDC. Se observaron altas frecuencias de punto P del protostílido, pliegue acodado, patrón cuspídeo, número de cúspides y cúspide 6 en los dientes deciduos; y de crowding, winging, forma de pala, reducción de hipocono, punto $\mathrm{P}$ del protostílido, patrón cuspídeo y cúspide 6 en los dientes permanentes.

Recibido: 03/03/2020 | Aceptado: 13/07/2020| Disponible en línea: 04/01/2021

Como citar este artículo: Hurtado, L.; Montenegro, L.; Pardo, C. Tipas, M.; Zuleta, A.; Moreno, S. y Moreno, F. (2021). Modos de herencia de la morfología dental en familias Misak del municipio de Silvia (Cauca, Colombia). Jangwa Pana 19(2), 11-33. doi: https://doi.org/10.21676/16574923.3884

\footnotetext{
${ }^{1}$ Correo electrónico: lizeth.hurtado@ correounivalle.edu.co

2 Correo electrónico: linda.montenegro@correounivalle.edu.co

${ }^{3}$ Correo electrónico: cindy.pardo@correounivalle.edu.co

${ }^{4}$ Correo electrónico: monica.tipas@correounivalle.edu.co
} 
No hubo dimorfismo sexual y se observó simetría bilateral. Hubo correspondencia entre la dentición decidua y permanente para la expresión de la cúspide de Carabelli, el número de cúspides y la cúspide 6. Se observó una tendencia de herencia de la expresión dicotómica presencia/ausencia de los RMDC desde las madres hacia los hijos. El grupo de indígenas Misak corresponde a una población con alta influencia del complejo dental mongoloide y baja influencia de los complejos dentales caucasoide y negroide de acuerdo con la expresión y variabilidad de los RMDC. La ausencia de dimorfismo sexual, la presencia de simetría bilateral y la correspondencia de algunos rasgos, evidencia un fuerte control genético en el modo de herencia (con tendencia desde las madres hacia los hijos) y una baja influencia del medio ambiente.

Palabras clave: Antropología dental; morfología dental; rasgos morfológicos dentales coronales; herencia; indígenas Misak.

Abstract: This is a cross-sectional descriptive study that identified the pattern of inheritance of 14 Non-metric Dental crown Traits (NDcT) from the frequency, variability, sexual dimorphism, bilateral asymmetry and correspondence between traits, in plaster models obtained from a group of ten families -mother, father and son/ daughter - who are part of the Misak community of Silvia (Cauca, Colombia). For deciduous dentition, Arizona State University Dental Anthropology System (ASUDAS, 1991) was used for crowding, winging and cusp 6, Grine (1986) for Carabelli cusp, Sciuli (1998) for protostylid, deflecting wrinkle, cuspid pattern and number of cusps, and Hanihara (1966) for cusp 7 in deciduous dentition; and for permanent dentition, ASUDAS for the 14 NDCT. High frequencies were observed of protostylid P-point, deflecting wrinkle, cuspid pattern, number of cusps and cusp 6 in deciduous teeth; as well as in permanent teeth crowding, winging, shovel shape, hypocono reduction, protostylid $\mathrm{P}$ point, cuspid pattern and cusp 6 . There was not sexual dimorphism and bilateral symmetry was observed. There was correspondence between the deciduous teeth and permanent for the expression of the Carabelli cusp, the number of cups and the 6 cusp. It was observed a tendency of the dichotomous presence/absence of the NDCT inheritance from the mothers to the children. According to the NDCT expression and variability the Misak indigenous group corresponds to a population with a considerable influence of the Mongoloid dental complex and a minor influence of Caucasoid and Negroid dental complexes. The absence of sexual dimorphism, the presence of bilateral symmetry, and the correspondence of some traits, evidence a strong genetic control in the inheritance mode (with a tendency from mothers to children) and a low influence of the environment.

Keywords: Dental anthropology; dental morphology; non-metric dental crown traits; inheritance; Misak indigenous.

\section{Introducción}

A tooth! A tooth! My kingdom for a tooth! Thomas Huxley (1858)

En el contexto de la antropología dental, el estudio morfológico de la dentición humana decidua y permanente se ha centrado en la observación, el registro, el análisis y la comprensión de poco más de 20 rasgos morfológicos dentales, de entre los más de 100 que se han reportado en la literatura especializada, cuya expresión y varibilidad en la corona y la raíz de incisivos, caninos, premolares y molares han resultado de gran utilidad para comprender las variaciones anatómicas, en consideración con el patrón étnico, la distribución geográfica y los procesos de adaptación de las poblaciones humanas pasadas y presentes (Scott y Turner II, 1997, 1998; Alt, Rosing y Teschler-Nicola, 1998; Rodríguez, 2003).

De esta forma, los Rasgos Morfológicos Dentales Coronales (RMDC) se han constituido en variantes taxonómicas o unidades de variación fenotípicas de la morfología dental, cuya expresión hace parte del fenotipo — expresión física del genotipo — de un individuo; además, dada su fuerte base hereditaria, del fenotipo de una población (Rodríguez, 2003; Zoubov, 1998). 
En este sentido, los RMDC más usados en el análisis fenético poblacional — dada su alta estabilidad genética - han sido los incisivos en forma de pala, la cúspide de Carabelli, la reducción del hipocono, el pliegue acodado, el patrón cuspídeo, el protostílido, la cúspide 6 y la cúspide 7 (Mayhall, 2000; Moreno y Moreno, 2007).

A través de diferentes estudios y durante 10 años — desde 1967 (Turner II) hasta 1977 (Turner II y Hanihara) - , Turner estudió las frecuencias de los incisivos en forma de pala, la cúspide de Carabelli, la reducción del hipocono y el protostílido para determinar si las frecuencias de estos RMDC correspondían con el modelo de codominancia genética propuesto por Kraus (1952) como modo de herencia de la morfología dental.

Tanto con estudios poblacionales como familiares, se ha podido concluir que los RMDC son variables cuasicontinuas con una forma de herencia poligénica — se han identificado más de trescientos genes implicados en la odontogénesis (Thesleff, 2006) -; por tanto, al caracterizar, agrupar y comparar las poblaciones de acuerdo a la frecuencia y la variabilidad fenotípica de los RMDC, se pudo hacer alusión a la frecuencia y la variabilidad genética de la morfología dental de una población, de una familia y de un individuo (Townsend, Bockmann, Hughes y Brook, 2012). No obstante, no se conocen todos los mecanismos por los cuales diferentes genes conforman la expresión morfológica de un rasgo durante la odontogénesis (Hugjes y Townsend, 2013a).

Sin embargo, desde la última década del siglo XX y con los avances técnicos del análisis genómico humano, el conocimiento de los genes que determinan la identidad de estructuras individuales durante la embriogénesis (genes homeóticos) ha permitido aproximarse a la comprensión de que un número finito de genes interactúan en módulos de desarrollo para constituir la forma o fenotipo de un RMDC. Esto ha dejado de lado las teorías que plantean una relación individual entre un RMDC y un gen específico o que muchos genes actúan por su lado generando pequeños efectos morgenéticos específicos en los dientes. De esa forma se ha comprobado en diferentes estudios de embriología, comparada con modelos murinos (Thesleff, Vaahtokari y Partanen, 1995; Thesleff y Sahlberg, 1996; Thesleff y Sharpe, 1997; Jernvall y Jung, 2000).

Por su parte, la investigación genética a partir de la expresión fenotípica de RMDC se ha centrado en el estudio de gemelos monocigotos y dicigóticos, encontrando valores de hasta el $90 \%$ de heredibilidad. Sin embargo, dadas las diferentes frecuencias y la amplia variabilidad de los RMDC en las poblaciones humanas presentes respecto a la distribución geográfica y al patrón étnico, serán la deriva genética y las presiones medio ambientales las que macroevolutivamente expliquen los modos de herencia (Townsend, Hughes, Luciano, Bockmann y Brook, 2009),

Debido a que la dentición humana se forma desde la sexta semana de desarrollo intrauterino — durante las diferentes etapas sucedáneas de la odontogénesis - y finaliza cerca de los 16 años de vida postnatal, serán inicialmente los factores genéticos y epigenéticos, y posteriormente los factores ambientales, los que regulen e influyan respectivamente la expresión y la variabilidad morfológica de los RMDC (Reyes, Bonomie, Guevara, Palacios, Malgosa, Chimenos, Jordana, García-Sívoli, 2010). A partir de un complejo sistema de 
regulación genética y señalización molecular (relaciones epitelio-mesenquimáticas, conformación de campos morfogenéticos, clones morfogenéticos, expresión de genes homeobox, probables efectos mutacionales reductivos), que da como resultado una serie de variantes alélicas que direccionan a los individuos hacia un umbral fenotípico - efecto umbral de la variación cuasicontinua - en presencia de un fondo poligénico (Osborn, 1888; Butler, 1956, 1972; McCollum y Sharpe, 2001; Mitsiadis y Smith, 2006), se han constituido diferentes aspectos morfofuncionales característicos de la dentición humana, como son la bifiodoncia (denticiones decidua y permanente), las cuatro clases de dientes (p. e. incisivos) con sus respectivos tipos de dientes (p. e. incisivos centrales), la organización por arcos dentales (superior e inferior), la simetría bilateral a partir de la línea media (derecha e izquierda), el dimorfismo sexual (mujeres y hombres), las dimensiones dentales (p. e. área del polígono oclusal) y la morfología dental (rasgos morfológicos). Todas estas características obedecen no solo a la manera como interactúan los diferentes niveles de organización biológica (moléculas, células, estructuras celulares, tejidos, estructuras tisulares y órganos), sino también a diferentes fenómenos emergentes que presionan a los individuos de un grupo poblacional, desafiando su capacidad de adaptación a través del tiempo (fenómeno direccional transgeneracional) y espacio (factores aleatorios como migraciones, contactos, aislamientos y mestizaje). En términos generales, la frecuencia, la variabilidad, el dimorfismo sexual, la simetría bilateral y la correspondencia entre rasgos de los RMDC se ha podido atribuir a los efectos genéticos, epigenéticos y medio ambientales que actúan sobre el individuo (durante toda su vida), sobre una familia (durante las generaciones) y sobre una población (durante todas las generaciones) (Brook y Brook-O’Donnell, 2013).

De esta forma, la morfología dental, durante la odontogénesis en el primer arco faríngeo específicamente en la lámina dentaria-, se modela a partir de la expresión recíproca poligénica desde el ectodermo para conformar los diferentes campos morfogenéticos y para establecer dominios específicos de la expresión génica homeobox (genes estructurales HOX) desde el ectomesénquima subyacente, fundamentales para configurar la morfología de cada tipo de diente (Cobourne y Mitsiadis, 2006).

A partir de estos hallazgos, Townsend, Harris, Lesot, Clauss y Brook (2009), a través de sus estudios de la morfología y las dimensiones dentales en gemelos, unificaron las teorías moleculares (genética), celulares (histoembriología) y antropológicas (morfología) para generar un solo modelo multifactorial que explique la configuración morfológica de los dientes, su amplia variabilidad y, tal como se mencionó, los diferentes niveles de organización biológica (moléculas, células, estructuras celulares, tejidos, estructuras tisulares y órganos) que para este nivel de complejidad incluye al organismo y las poblaciones. Así, en el contexto antropológico y forense, los estudios comparativos de la expresión y la variación de la morfología dental entre los individuos que conforman una población y entre diferentes poblaciones humanas, se constituye en una herramienta de gran utilidad para determinar los cambios evolutivos - a nivel micro durante el desarrollo pre y postnatalque ocurren a lo largo del tiempo en respuesta a la distribución geográfica y al medio ambiente. De esta forma, se ha podido comprobar que las variaciones de la morfología de los dientes (expresión de los RMDC), aunque en un estado evolutivo muy conservado, están sujetas a factores genéticos y ambientales que influyen la etapa morfogénica de la odontogénesis, generando cambios específicos entre ambas denticiones (deciduos vs. permanentes), clases de dientes (incisivos vs. caninos), tipos de dientes (incisivos centrales 
vs. incisivos laterales), arcos dentales (primeros molares superiores vs. primeros molares inferiores), hemiarcadas dentales (canino derecho vs. canino izquierdo), sexo (mujeres vs. hombres), miembros de una familia (padres vs. hijos), generaciones (abuelos vs. nietos), grupos étnicos (mestizos caucasoides vs. afrodescendientes) y poblaciones (sinodontes vs. indígenas contemporáneos) (Townsend, Dempsey y Richards, 1999; Hughes y Townsend, 2013b).

En este sentido, esta investigación tuvo como objetivo identificar el modo de herencia de la morfología dental en un grupo de familias misak del municipio de Silvia (Cauca, Colombia), a partir de la frecuencia y la variabilidad de 14 RMDC. El nuevo conocimiento generado en este estudio podrá contribuir con los procesos de autoreconocimiento y sentido de pertenencia étnico de la comunidad indígena ancestral misak que habita en el suroccidente colombiano.

El pueblo indígena guambiano, misag o misak, corresponde a un grupo étnico que se distribuye en Colombia entre los departamentos del Huila (municipios de La Plata y La Argentina) y del Cauca (municipios de Piendamó, Morales, Jámbalo, Caldono, Totoró, Toribío y Silvia). Históricamente, sin llegar a un consenso, su origen ha sido trazado en el Valle del Pubenza, a partir de una sociedad prehispánica reconocida como los pubenses, cuyo territorio fue conquistado por Sebastián de Belalcázar y manejado socioeconómicamente durante la colonia a través de la encomienda. Posteriormente, en 1635, por acción del cacique Juan Tama, se recuperaron los derechos de propiedad de la tierra ante la corona española y se configuraron los resguardos de Guambía, Quisgó, Pitayó, Quichaya, Jambaló, Caldono y Pueblo Nuevo. En la actualidad, luego de resistir la presión social, económica, política y demográfica durante los siglos XIX y XX, los resguardos fueron protegidos por la Constitución Política colombiana de 1991 (Pachón, 1996; Benavidez, Coronel y Ruíz, 2014). Sin embargo, de lo que era su antiguo territorio solo queda una pequeña parte, siendo los resguardos de Guambía y Quisgó, en el municipio de Silvia, los que concentran la mayor densidad de población misak (Vázquez, 2000). De acuerdo con el Censo de 2018, del total de la población colombiana, el 4,4\% (1 905617 individuos) se autorreconocen como indígenas, de los cuales em 1,13\% (21 713) corresponden al grupo étnico misak. De estos últimos, el $54 \%$ (11 877 individuos) se distribuyen en el casco urbano y en las veredas rurales de dicho municipio (DANE, 2019).

Investigaciones previas (García, Gustín, Quiñonez, Sacanamboy, Torres, Triana, Valencia, Rojas, Gómez, Díaz, Sánchez y Moreno, 2015; Gutiérrez, Revelo, Burgos, Zambrano, Cerón y Tello, 2017; García, Gustín, Quiñonez, Sacanamboy, Torres, Triana, Rojas, Gómez, Díaz y Moreno, 2018) caracterizaron la expresión de diferentes RMDC y concluyeron que las muestras pertenecientes al grupo étnico misak evidencian una pertenencia al complejo dental mongoloide sinodonte, con baja influencia de mestizaje con grupos de mestizos caucasoides y afrodescendientes, con quienes comparte el mismo territorio geográfico.

\section{Materiales y métodos}

Este fue un estudio descriptivo transversal cuantitativo que identificó el modo de herencia de la morfología dental a partir de la frecuencia, variablidad, dimorfismo sexual, asimetría bilateral y correspondencia de 14 RMDC en incisivos superiores permanentes (winging, 
crowding, incisivos centrales en forma de pala, incisivos centrales en doble pala, incisivos laterales en pala e incisivos laterales en doble pala), molares superiores deciduos y permanentes (cúspide de Carabelli y reducción del hipocono) y molares inferiores decíduos y permanentes (protostílido, pliegue acodado, patrón cuspídeo, número de cúspides, cúspide 6 y cúspide 7). Si bien ASUDAS es un método empleado para dentición permanente, y dado que los métodos utilizan escalas de observación diferentes (gradación y dicotomía presencia/ausencia), se empleó el modelo de conversión propuesto por Edgar y Lease (2007).

La muestra estuvo constituida por 10 familias - madre, padre e hijo(a) - que forman parte de la comunidad misak de las veredas El Cacique y Peña del Corazón, del resguardo Guambía del municipio de Silvia (Cauca, Colombia), distribuidos en ambos sexos -16 mujeres (10 madres y 6 hijas) y 14 hombres (10 padres y 4 hijos) -; todos ellos autoreconocidos como indígenas misak.

Una vez obtenido el aval del Comité Institucional de Revisión de Ética Humana (CIREH) de la Facultad de Salud de la Universidad del Valle — y de acuerdo con la resolución 008430 del Ministerio de la Protección Social (1993) y con la Declaración de Helsinki (1964)—, se visitaron 30 familias con el esquema padre, madre e hijo(a). A ellos se les realizó un examen intraoral para incluir en el estudio a 10 familias cuyos integrantes no contaran con desgastes en los dientes, caries o tratamientos odontológicos que dificultaran la observación de los RMDC tenidos en cuenta en el estudio, y quienes, además, asintieron y consintieron su participación. El acceso a la población fue facilitado por el Hospital Mama Dominga del muncipio de Silvia.

Posteriormente, se tomaron 60 impresiones (30 superiores y 30 inferiores) de los arcos dentales, con alginato Tropicalgin $\AA$ Zhermack®, a través de cubetas plásticas tipo Coe®, para obtener los modelos de estudio en yeso tipo III comercial americano. Además, se realizó la observación de los RMDC tenidos en cuenta en este estudio a través de diferentes sistemas de registro de acuerdo a la dentición decidua Arizona State University Dental Anthropology System —ASUDAS — para cúspide 6 (Turner II, Nichol y Scott, 1991); Grine (1986), para cúspide de Carabelli; Sciulli (1998), para protostílido, pliegue acodado, patrón cuspídeo y número de cúspides; Hanihara (1966), para cúspide 7; y, de acuerdo a la dentición permanente, ASUDAS para los 14 RMDC (Turner II, Nichol y Scott, 1991) (Tabla 1).

Tabla 1. RMDC empleados en esta investigación

\begin{tabular}{|c|c|c|c|c|c|}
\hline \multirow{2}{*}{ Rasgo } & \multirow{2}{*}{ Diente } & \multirow{2}{*}{ Gradación } & \multicolumn{2}{|c|}{ Grados de expresión } & \multirow{2}{*}{$\begin{array}{l}\text { Método de } \\
\text { referencia }\end{array}$} \\
\hline & & & Rango & Presencia & \\
\hline Crowding & UI2 & $\begin{array}{l}\text { 0. Ausente } \\
\text { 1. Vestibular } \\
\text { 2. Palatino }\end{array}$ & $0-2$ & $1-2$ & $\begin{array}{l}\text { ASUDAS, } \\
\text { Turner II, Nichol } \\
\text { y Scott (1991) }\end{array}$ \\
\hline Winging & UI1 & $\begin{array}{l}\text { 0. Ausente } \\
\text { 1. Bilateral } \\
\text { 2. Unilateral } \\
\text { 3. Unilateral fuerte } \\
\text { 4. Contralateral }\end{array}$ & $0-4$ & $1-4$ & $\begin{array}{l}\text { ASUDAS, } \\
\text { Turner II, Nichol } \\
\text { y Scott (1991) }\end{array}$ \\
\hline
\end{tabular}




\begin{tabular}{|c|c|c|c|c|c|}
\hline $\begin{array}{l}\text { Incisivos } \\
\text { en pala }\end{array}$ & $\begin{array}{l}\text { uil/ } \\
\text { UP1 }\end{array}$ & $\begin{array}{l}\text { 0. Ausente } \\
\text { 1. Suave } \\
\text { 2. Trazado } \\
\text { 3. Semi-pala } \\
\text { 4. Semi-pala marcado } \\
\text { 5. Pala } \\
\text { 6. Pala Marcado } \\
\text { 7. Forma de barril }\end{array}$ & $0-7$ & $2-7$ & $\begin{array}{l}\text { ASUDAS, } \\
\text { Turner II, Nichol } \\
\text { y Scott (1991). La } \\
\text { observación de } \\
\text { este rasgo fue } \\
\text { ajustada de } \\
\text { acuerdo a la } \\
\text { escala de } \\
\text { conversión de } \\
\text { Egar y Lease } \\
\text { (2007). }\end{array}$ \\
\hline $\begin{array}{l}\text { Doble } \\
\text { pala }\end{array}$ & $\begin{array}{l}\text { UP1/ } \\
\text { UP2 }\end{array}$ & $\begin{array}{l}\text { 0. Ausente } \\
\text { 1. Suave } \\
\text { 2. Trazo } \\
\text { 3. Semi-doble pala } \\
\text { 4. Doble pala } \\
\text { 5. Doble pala marcada } \\
\text { 6. Doble pala externo } \\
\end{array}$ & $0-6$ & $2-6$ & $\begin{array}{l}\text { ASUDAS, } \\
\text { Turner II, Nichol } \\
\text { y Scott (1991) }\end{array}$ \\
\hline $\begin{array}{l}\text { Cúspide de } \\
\text { Carabelli }\end{array}$ & um1 & $\begin{array}{l}\text { 0. Ausente } \\
\text { 1. Depresión en forma de U o Y } \\
\text { 2. Dos surcos paralelos } \\
\text { 3. Cúspide pequeña } \\
\text { 4. Cúspide de vértice libre }\end{array}$ & $0-4$ & $3-4$ & Grine (1986) \\
\hline $\begin{array}{l}\text { Cúspide de } \\
\text { Carabelli }\end{array}$ & UM1 & $\begin{array}{l}\text { 0. Ausente } \\
\text { 1. Surco presente } \\
\text { 2. Fosa presente } \\
\text { 3. Pequeña depresión en forma de } \\
\text { Y } \\
\text { 4. Gran depresión en forma de Y } \\
\text { 5. Cúspide pequeña } \\
\text { 6. Cúspide mediana } \\
\text { 7. Cúspide de vértice libre }\end{array}$ & $0-7$ & $2-7$ & $\begin{array}{l}\text { ASUDAS, } \\
\text { Turner II, } \\
\text { Nichol y Scott } \\
\text { (1991) }\end{array}$ \\
\hline $\begin{array}{l}\text { Reducción } \\
\text { del hipocono }\end{array}$ & $\begin{array}{l}\text { UM1/ } \\
\text { UM2 }\end{array}$ & $\begin{array}{l}\text { 0. Ausente } \\
\text { 1. Débil surco presente en el sitio } \\
\text { 2. Presente cúspide muy pequeña } \\
\text { 3. Presente cúspide pequeña } \\
\text { 3.5 Cúspide de tamaño moderado } \\
\text { 4. Cúspide de tamaño grande } \\
\text { 5. Cúspide de gran tamaño }\end{array}$ & $0-5$ & $2-5$ & $\begin{array}{l}\text { ASUDAS, } \\
\text { Turner II, } \\
\text { Nichol y Scott } \\
\text { (1991) }\end{array}$ \\
\hline Protostílido & $\operatorname{lm} 1$ & $\begin{array}{l}\text { 0. Ausente. } \\
\text { 1. Fosa o surco } \\
\text { 2. Cúspide }\end{array}$ & $0-2$ & 2 & Sciulli (1998) \\
\hline Protostílido & $\begin{array}{l}\text { LM1/ } \\
\text { LM2 }\end{array}$ & $\begin{array}{l}\text { 0. Ausente } \\
\text { 1. Fosa (foramen secum) } \\
\text { 2. Surco vestibular curvado a } \\
\text { distal } \\
\text { 3. Surco distal desde surco } \\
\text { vestibular } \\
\text { 4. Surco más pronunciado } \\
\text { 5. Surco fuerte } \\
\text { 6. Surco cruza superficie } \\
\text { vestibular } \\
\text { 7. Cúspide de vértice libre } \\
\end{array}$ & $0-7$ & $2-7$ & $\begin{array}{l}\text { ASUDAS, } \\
\text { Turner II, } \\
\text { Nichol y Scott } \\
\text { (1991) }\end{array}$ \\
\hline $\begin{array}{l}\text { Pliegue } \\
\text { acodado }\end{array}$ & $\operatorname{lm} 1$ & $\begin{array}{l}\text { 0. Ausente } \\
\text { 1. Presente }\end{array}$ & $0-1$ & 1 & Sciulli (1998) \\
\hline
\end{tabular}




\begin{tabular}{|c|c|c|c|c|c|}
\hline $\begin{array}{l}\text { Pliegue } \\
\text { acodado }\end{array}$ & $\begin{array}{l}\text { LM1/ } \\
\text { LM2 }\end{array}$ & $\begin{array}{l}\text { 0. Ausente } \\
\text { 1. Constricción poco pronunciada } \\
\text { 2. Constricción marcada } \\
\text { 3. Forma de L } \\
\end{array}$ & $0-3$ & $2-3$ & \begin{tabular}{|l} 
ASUDAS, \\
Turner II, \\
Nichol y Scott \\
$(1991)$ \\
\end{tabular} \\
\hline $\begin{array}{l}\text { Patrón } \\
\text { cuspídeo }\end{array}$ & $\operatorname{lm} 1$ & $\begin{array}{l}\text { +. Cúspides } 1,2,3 \text { y } 4 \text { en } \\
\text { contacto } \\
\text { X. Cúspides } 1 \text { y } 4 \text { en contacto } \\
\text { Y. Cúspides } 2 \text { y } 3 \text { en contacto } \\
\end{array}$ & $\mathrm{Y},+, \mathrm{X}$ & $\mathrm{Y}$ & Sciulli (19980) \\
\hline $\begin{array}{l}\text { Patrón } \\
\text { cuspídeo }\end{array}$ & $\begin{array}{l}\text { LM1/ } \\
\text { LM2 }\end{array}$ & $\begin{array}{l}\text { Y. Cúspides } 2 \text { y } 3 \text { en contacto } \\
\text { +. Cúspides } 1,2,3 \text { y } 4 \text { en } \\
\text { contacto } \\
\text { X. Cúspides } 1 \text { y } 4 \text { en contacto }\end{array}$ & $\mathrm{Y},+, \mathrm{X}$ & $\mathrm{Y}$ & $\begin{array}{l}\text { ASUDAS, } \\
\text { Turner II, } \\
\text { Nichol y Scott } \\
(1991)\end{array}$ \\
\hline $\begin{array}{l}\text { Número de } \\
\text { cúspides }\end{array}$ & $\operatorname{lm} 1$ & $\begin{array}{l}2 \text { Cúspides } 1 \text { y } 2 \\
3 \text { Cúspides } 1,2 \text { y } 3 \\
4 \text { Cúspides } 1,2,3 \text { y } 4 \\
5 \text { Cúspides } 1,2,3,4 \text { y } 5 \\
6 \text { Cúspides } 1,2,3,4,5 \text { y } 6 \\
7 \text { Cúspides: } 1,2,3,4,5,6 \text { y } 7 \\
\text { Más de siete cúspides }\end{array}$ & $2-8$ & 5 & Sciulli (1998) \\
\hline $\begin{array}{l}\text { Número de } \\
\text { cúspides }\end{array}$ & $\begin{array}{l}\text { LM1/ } \\
\text { LM2 }\end{array}$ & $\begin{array}{l}4 \text { Cúspides } 1,2,3 \text { y } 4 \\
5 \text { Cúspides } 1,2,3,4 \text { y } 5 \\
6 \text { Cúspides } 1,2,3,4,5 \text { y } 6 \\
7 \text { Cúspides } 1,2,3,4,5,6 \text { y } 7 \\
\end{array}$ & $4-6$ & 5 & \begin{tabular}{|l} 
ASUDAS, \\
Turner II, \\
Nichol y Scott \\
$(1991)$ \\
\end{tabular} \\
\hline Cúspide 6 & $\begin{array}{l}\text { lm1/ } \\
\text { LM1/ } \\
\text { LM2 }\end{array}$ & $\begin{array}{l}\text { 0. Ausente } \\
\text { 1. Cúspide } 6<<\text { Cúspide } 5 \\
\text { 2. Cúspide } 6<\text { Cúspide } 5 \\
\text { 3. Cúspide } 6=\text { Cúspide } 5 \\
\text { 4. Cúspide } 6>\text { Cúspide } 5 \\
\text { 5. Cúspide } 6>>\text { Cúspide } 5\end{array}$ & $0-5$ & $1-5$ & $\begin{array}{l}\text { ASUDAS, } \\
\text { Turner II, } \\
\text { Nichol y Scott } \\
\text { (1991) }\end{array}$ \\
\hline Cúspide 7 & $\operatorname{lm} 1$ & $\begin{array}{l}\text { 0. Ausente } \\
\text { 1. Rastro } \\
\text { 2. Pequeña cúspide } \\
\text { 3. Bien desarrollada } \\
\end{array}$ & $0-3$ & $1-3$ & Hanihara (1966) \\
\hline Cúspide 7 & $\begin{array}{l}\text { LM1/ } \\
\text { LM2 }\end{array}$ & $\begin{array}{l}\text { 0. Ausente } \\
\text { 1. Trazos } \\
\text { 1A. Trazos más marcados } \\
\text { 2. Cúspide pequeña } \\
\text { 3. Cúspide mediana } \\
\text { 4. Cúspide grande } \\
\end{array}$ & $0-4$ & $1-4$ & $\begin{array}{l}\text { ASUDAS, } \\
\text { Turner II, } \\
\text { Nichol y Scott } \\
(1991)\end{array}$ \\
\hline
\end{tabular}

No sobra manifestar que los observadores fueron estandarizados para la observación y el registro de los RMDC, de tal forma que el grado de fiabilidad a través de la prueba Kappa (software Stata® versión 6.0) fue estimado para intraobservador 1 (93\% y 94,6 \%) e intraobservador $2(92 \%$ y $91 \%$ ) de acuerdo con lo descrito en la literatura (Nichol y Turner II, 1986).

Durante la observación, la información fue registrada en una hoja electrónica (Microsoft ${ }^{\circ}$ Excel®) y procesada en el software IBM SPSS Statistics ${ }^{\circledR} 22.0$ para obtener las frecuencias de la expresión (dicotomía presencia/ausencia) y la variabilidad (gradación), el dimorfismo sexual (prueba de Mann-Whitney U), la asimetría bilateral (prueba de Wilcoxon) y la correspondencia entre rasgos (prueba de Wilcoxon). Una $p<0,05$ fue considerada 
estadísticamente significativa. De igual forma, a partir de la frecuencia de siete de los RMDC tenidos en cuenta en este estudio (incisivos en pala, cúspide Carabelli, patrón cuspídeo, pliegue acodado, protostílido, cúspide 6 y cúspide 7), se obtuvo un dendograma desde una matriz de distancias biológicas, a través de la clasificación de conglomerados jerárquicos mediante el método de Ward, la distancia euclídea al cuadrado y la estandarización por Z, entre diferentes poblaciones mundiales (Turner II, 1984; Hanihara, 1992; Irish, 1998; Rodríguez, 2003; Edgar, 2007) y colombianas (Rodríguez, 2003; Moreno, Moreno, Díaz, Bustos y Rodríguez, 2004; Bravo, Buitrago y Zarante, 2003; Villar y Granobles, 2007; Rocha, Rivas y Moreno, 2007; Delgado-Burbano, 2007; Marcovich, Prado, Díaz, Ortiz, Martínez y Moreno, 2012; Díaz, García, Hernández, Palacio, Ruiz, Velandia, Villavicencio y Moreno, 2014; García, Gustín, Quiñonez, Sacanamboy, Torres, Triana, Valencia, Rojas, Gómez y Moreno, 2015; Zúñiga, Moreno y Moreno, 2016; Pérez, Sánchez, Moreno y Moreno, 2017; Asprilla, Franco, Morales y Moreno, 2017).

Finalmente, se correlacionó la expresión de los 14 RMDC entre padres e hijos para estimar el modo de herencia a través de un análisis de correspondencia múltiple en el Software $R$ (Project for Statistical Computing), en el que se categorizó la dicotomía presencia/ausencia de cada rasgo morfológico, para identificar inicialmente la inercia de las variables observadas respecto a cada uno de los ejes de análisis, donde los primeros cinco valores propios estuvieron determinados de la siguiente manera: 0,1865, 0,1602, 0,09657, 0,09553 y 0,0814. Para que el análisis fuera posible, se escogieron los dos primeros ejes factoriales, los cuales recogieron el $34,6 \%$ de la variabilidad, con un $18,65 \%$ para el primero y un $16,02 \%$ para el segundo. De esta forma, se tomaron a los hijos, madres y padres para ser ubicados en los puntos dentro de las dos dimensiones seleccionadas y poder identificar los cuadrantes en donde los tres miembros de la familia presentaron la mayor tendencia.

\section{Resultados}

De acuerdo con la dicotomía presencia/ausencia, la frecuencia y la variabilidad de los RMDC (Tabla 2) en la dentición decidua fue alta para la forma medianamente marcada de pala de incisivos laterales $(96,7 \%)$, alta para el punto $\mathrm{P}$ del protostílido $(98,0 \%)$, para el pliegue acodado (76,6 \%), para el patrón cuspídeo en Y (89,0 \%), para el número de 5 cúspides $(93,3$ $\%$ ) y para expresiones de cúspide 6 de pequeño tamaño $(70,7 \%)$; y fue baja para cúspide de Carabelli (3,3\%), expresión cuspídea del protostílido (3,3\%) y para la cúspide 7 (3,3\%). En el caso de la dentición permanente, fue alta para crowding $(66,7 \%)$, para winging $(40,0 \%)$, para la forma medianamente marcada de pala de incisivos centrales $(60 \%)$, para la ausencia de reducción de hipocono $(83,4 \%)$, para el punto $\mathrm{P}$ del protostílido en primeros molares $(90,0 \%)$ y segundos molares $(92,0 \%)$, para el patrón cuspídeo en Y de los primeros (89 \%) y de los segundos molares $(76,7 \%)$, y para expresiones de cúspide 6 de pequeño tamaño en los primeros molares $(66,7 \%)$. También fue alta para la forma medianamente marcada de doble pala de incisivos centrales $(43,3 \%)$ e incisivos laterales $(43,3 \%)$, para el pliegue acodado en primeros molares $(46,7 \%)$, para el número de 5 cúspides $(36,7 \%$ ) y para expresiones de cúspide 6 de pequeño tamaño en los segundos molares (39,4\%); y baja para la cúspide de Carabelli en primeros $(13,4 \%)$ y segundos molares (totalmente ausente $0 \%$ ), para las expresiones cuspídeas del protostílido en primeros $(3,3 \%)$ y segundos molares $(6,7$ $\%)$, para el pliegue acodado en segundos molares $(33,3 \%)$, para el número de 5 cúspides $(20,0 \%)$ y para la cúspide 7 de primeros $(37,7 \%)$ y segundos molares $(19,9 \%)$. 
Tabla 2. Frecuencias RMDC de toda la muestra

\begin{tabular}{|c|c|c|c|}
\hline Rasgo & Diente & Gradación & $\%$ \\
\hline \multirow{3}{*}{ Crowding } & \multirow{3}{*}{ UI2 } & 0 & 33,3 \\
\hline & & 1 & 33,3 \\
\hline & & 2 & 33,4 \\
\hline \multirow{4}{*}{ Winging } & \multirow{4}{*}{ UI1 } & 0 & 60,0 \\
\hline & & 1 & 30,0 \\
\hline & & 2 & 6,3 \\
\hline & & 3 & 3,7 \\
\hline \multirow{3}{*}{ Incisivos en pala } & \multirow{3}{*}{ uil } & 0 & 3,3 \\
\hline & & 1 & 50,0 \\
\hline & & 2 & 46,7 \\
\hline \multirow{3}{*}{ Incisivos en pala } & \multirow{3}{*}{ UI1 } & 0 & 13,3 \\
\hline & & 1 & 60,0 \\
\hline & & 3 & 26,6 \\
\hline \multirow{3}{*}{ Doble pala } & \multirow{3}{*}{ UI1 } & 0 & 40,0 \\
\hline & & 1 & 16,7 \\
\hline & & 2 & 43,3 \\
\hline \multirow{4}{*}{ Doble pala } & \multirow{4}{*}{ UP2 } & 0 & 43,3 \\
\hline & & 1 & 13,3 \\
\hline & & 2 & 40,0 \\
\hline & & 3 & 3,3 \\
\hline \multirow{4}{*}{ Cúspide de Carabelli } & \multirow{4}{*}{ um1 } & 0 & 66,7 \\
\hline & & 1 & 23,3 \\
\hline & & 2 & 6,7 \\
\hline & & 5 & 3,3 \\
\hline \multirow{4}{*}{ Cúspide de Carabelli } & \multirow{4}{*}{ UM1 } & 0 & 53,3 \\
\hline & & 1 & 33,3 \\
\hline & & 2 & 6,7 \\
\hline & & 3 & 6,7 \\
\hline \multirow{2}{*}{ Cúspide de Carabelli } & \multirow{2}{*}{ UM2 } & 0 & 96,6 \\
\hline & & 1 & 3,3 \\
\hline \multirow{6}{*}{$\begin{array}{l}\text { Reducción del } \\
\text { hipocono }\end{array}$} & \multirow{6}{*}{ UM1 } & 0 & 3,3 \\
\hline & & 1 & 13,3 \\
\hline & & 2 & 6,7 \\
\hline & & 3 & 20,0 \\
\hline & & 4 & 40,0 \\
\hline & & 5 & 16,7 \\
\hline \multirow{4}{*}{$\begin{array}{l}\text { Reducción del } \\
\text { hipocono }\end{array}$} & \multirow{4}{*}{ UM2 } & 0 & 66,7 \\
\hline & & 1 & 13,3 \\
\hline & & 2 & 10,0 \\
\hline & & 3 & 10,0 \\
\hline & & 0 & 86,7 \\
\hline Protostílido & $\operatorname{lm} 1$ & 1 & 10,0 \\
\hline & & 2 & 3,3 \\
\hline & & 0 & 40,0 \\
\hline Protostílido & LM1 & 1 & 56,7 \\
\hline & & 2 & 3,3 \\
\hline & & 0 & 53,3 \\
\hline Protostílido & LM2 & 1 & 40,0 \\
\hline & & 3 & 6,7 \\
\hline Pliegue acodado & $\operatorname{lm} 1$ & 0 & 23,4 \\
\hline
\end{tabular}




\begin{tabular}{|c|c|c|c|}
\hline & & 1 & 76,6 \\
\hline \multirow{3}{*}{ Pliegue acodado } & \multirow{3}{*}{ LM1 } & 0 & 53,3 \\
\hline & & 2 & 6,7 \\
\hline & & 3 & 40,0 \\
\hline \multirow{2}{*}{ Pliegue acodado } & \multirow{2}{*}{ LM2 } & 0 & 66,7 \\
\hline & & 1 & 33,3 \\
\hline \multirow{3}{*}{ Patrón cuspídeo } & \multirow{3}{*}{$\operatorname{lm} 1$} & $\mathrm{Y}$ & 89,0 \\
\hline & & + & 6,0 \\
\hline & & $\mathrm{X}$ & 5,0 \\
\hline \multirow{3}{*}{ Patrón cuspídeo } & \multirow{3}{*}{ LM1 } & $\mathrm{Y}$ & 82,3 \\
\hline & & + & 15,7 \\
\hline & & $X$ & 2,0 \\
\hline \multirow{3}{*}{ Patrón cuspídeo } & \multirow{3}{*}{ LM2 } & $\mathrm{Y}$ & 76,7 \\
\hline & & + & 23,3 \\
\hline & & $X$ & 0,0 \\
\hline \multirow{3}{*}{ Número de cúspides } & \multirow{3}{*}{$\operatorname{lm} 1$} & 5 & 93,3 \\
\hline & & 6 & 3,4 \\
\hline & & 7 & 3,3 \\
\hline \multirow{3}{*}{ Número de cúspides } & \multirow{3}{*}{ LM1 } & 5 & 36,7 \\
\hline & & 6 & 36,7 \\
\hline & & 7 & 26,7 \\
\hline \multirow{4}{*}{ Número de cúspides } & \multirow{4}{*}{ LM2 } & 4 & 60,0 \\
\hline & & 5 & 20,0 \\
\hline & & 6 & 6,7 \\
\hline & & 7 & 13,3 \\
\hline \multirow{3}{*}{ Cúspide 6} & \multirow{3}{*}{$\operatorname{lm} 1$} & 0 & 93,4 \\
\hline & & 1 & 3,3 \\
\hline & & 2 & 3,3 \\
\hline \multirow{5}{*}{ Cúspide 6} & \multirow{5}{*}{ LM1 } & 0 & 30,0 \\
\hline & & 1 & 33,3 \\
\hline & & 2 & 20,0 \\
\hline & & 3 & 13,3 \\
\hline & & 5 & 3,3 \\
\hline \multirow{4}{*}{ Cúspide 6} & \multirow{4}{*}{ LM2 } & 0 & 60,6 \\
\hline & & 1 & 10,0 \\
\hline & & 2 & 16,7 \\
\hline & & 3 & 6,7 \\
\hline \multirow{2}{*}{ Cúspide 7} & $\operatorname{lm} 1$ & 0 & 96,3 \\
\hline & 1111 & 1 & 3,3 \\
\hline & & 0 & 60,0 \\
\hline & & 1 & 2,3 \\
\hline Cúspide 7 & LM1 & 2 & 16,7 \\
\hline & & 3 & 10,0 \\
\hline & & 4 & 10,0 \\
\hline & & 0 & 74,4 \\
\hline & & 1 & 6,7 \\
\hline Cúspide 7 & LM2 & 2 & 3,3 \\
\hline & & 3 & 13,3 \\
\hline & & 4 & 3,3 \\
\hline
\end{tabular}

En términos generales, no hubo dimorfismo sexual con la excepción de la cúspide 6 de los segundos molares permanentes, en donde se observó una mayor expresión en las mujeres, 
asociada a la distribución de la muestra por sexo. Asimismo, se observó simetría bilateral en la expresión y la variabilidad de los RMDC (Tabla 3).

Tabla 3. Dimorfismo sexual y simetría bilateral de los 14 RMDC de toda la muestra

\begin{tabular}{|c|c|c|c|}
\hline Rasgo & Diente & $\begin{array}{c}\text { Dimpofismo sexual } \\
(\mathbf{p}<0,05)^{\mathrm{a}}\end{array}$ & $\begin{array}{c}\text { Simetría bilateral } \\
(\mathrm{p}<0,05)^{\mathrm{b}}\end{array}$ \\
\hline Crowding $^{\mathrm{c}}$ & UI2 & 0,229 & - \\
\hline Winging $^{\mathrm{c}}$ & UI1 & 0,905 & - \\
\hline Forma de pala & UI1 & 0,378 & 0,317 \\
\hline Forma de pala & UI2 & 0,863 & 0,655 \\
\hline Doble pala & UI1 & 0,170 & 0,317 \\
\hline Doble pala & UI2 & 0,048 & 0,748 \\
\hline Cúspide de Carabelli & um1 & 0,439 & 0,564 \\
\hline Cúspide de Carabelli & UM1 & 0,549 & 0,058 \\
\hline Cúspide de Carabelli & UM2 & 0,317 & 0,317 \\
\hline Reducción del hipocono & UM1 & 0,057 & 0,673 \\
\hline Reducción del hipocono & UM2 & 0,067 & 0,726 \\
\hline Protostílido & $\operatorname{lm} 1$ & 0,403 & 0,180 \\
\hline Protostílido & LM1 & 0,264 & 1,000 \\
\hline Protostílido & LM2 & 1,000 & 1,000 \\
\hline Pliegue acodado & $\operatorname{lm} 1$ & 0,881 & 1,000 \\
\hline Pliegue acodado & LM1 & 0,454 & 0,040 \\
\hline Pliegue acodado & LM2 & 1,000 & 1,000 \\
\hline Patrón cuspídeo & $\operatorname{lm} 1$ & 1,000 & 0,317 \\
\hline Patrón cuspídeo & LM1 & 0,203 & 0,564 \\
\hline Patrón cuspídeo & LM2 & 0,615 & 0,655 \\
\hline Número de cúspides & $\operatorname{lm} 1$ & 1,000 & 0,102 \\
\hline Número de cúspides & LM1 & 0,808 & 1,000 \\
\hline Número de cúspides & LM2 & 0,811 & 0,157 \\
\hline Cúspide 6 & $\operatorname{lm} 1$ & 1,000 & 0,180 \\
\hline Cúspide 6 & LM1 & 0,590 & 0,305 \\
\hline Cúspide 6 & LM2 & 0,488 & 0,066 \\
\hline Cúspide 7 & $\operatorname{lm} 1$ & 1,000 & 0,317 \\
\hline Cúspide 7 & LM1 & 0,438 & 1,000 \\
\hline Cúspide 7 & LM2 & 0,123 & 0,276 \\
\hline
\end{tabular}

a. Prueba de Mann-Whitney.

b. Prueba de Wilcoxon.

c. No se puede obtener simetría bilateral porque estos dos rasgos incluyen los dos dientes contralaterales.

El dendograma permitió observar que la muestra de indígenas misak de este estudio se agrupó con otras poblaciones indígenas colombianas en un mismo conglomerado, y se aproximó a dos conglomerados constituidos por poblaciones mestizas caucasoides y afrodescendientes con las que comparte el mismo territorio geográfico y con las que se ha mezclado, como consecuencia de diferentes procesos etnohistóricos ocurridos durante los últimos 500 años (Figura 1). 
Afrodescendientes Tumaco

Afrodescendientes Providencia

Sud-áfrica

Mestizos de Cartagena

Indígenas Emberá de Chocó

Indígenas Misak (este estudio)

Indigenas Colombianos

Indigenas Paeces

Indigenas Guambianos

Noroeste Europa

Europa

Norte de África

Mestizos caucasoides de Cali

Afrodescendientes Villarica

Afrodescendientes Puerto Tejada

Afrodescendientes Istmina

Americanos Negros

NYABG

Mestizos caucasoides de Chocó

Mestizos de Popayán

Afrodescendientes Guapi

Afrodescendientes Choco

África Sub-Sahara

Afrodescendientes de Cali

Sundadontes

Noreste Asia

Esquimales

Sinodontes

Indigenas Suramericanos

Noreste Siberia

Indígenas Norteamericanos

Chinos

Japonenses

Aleutianos

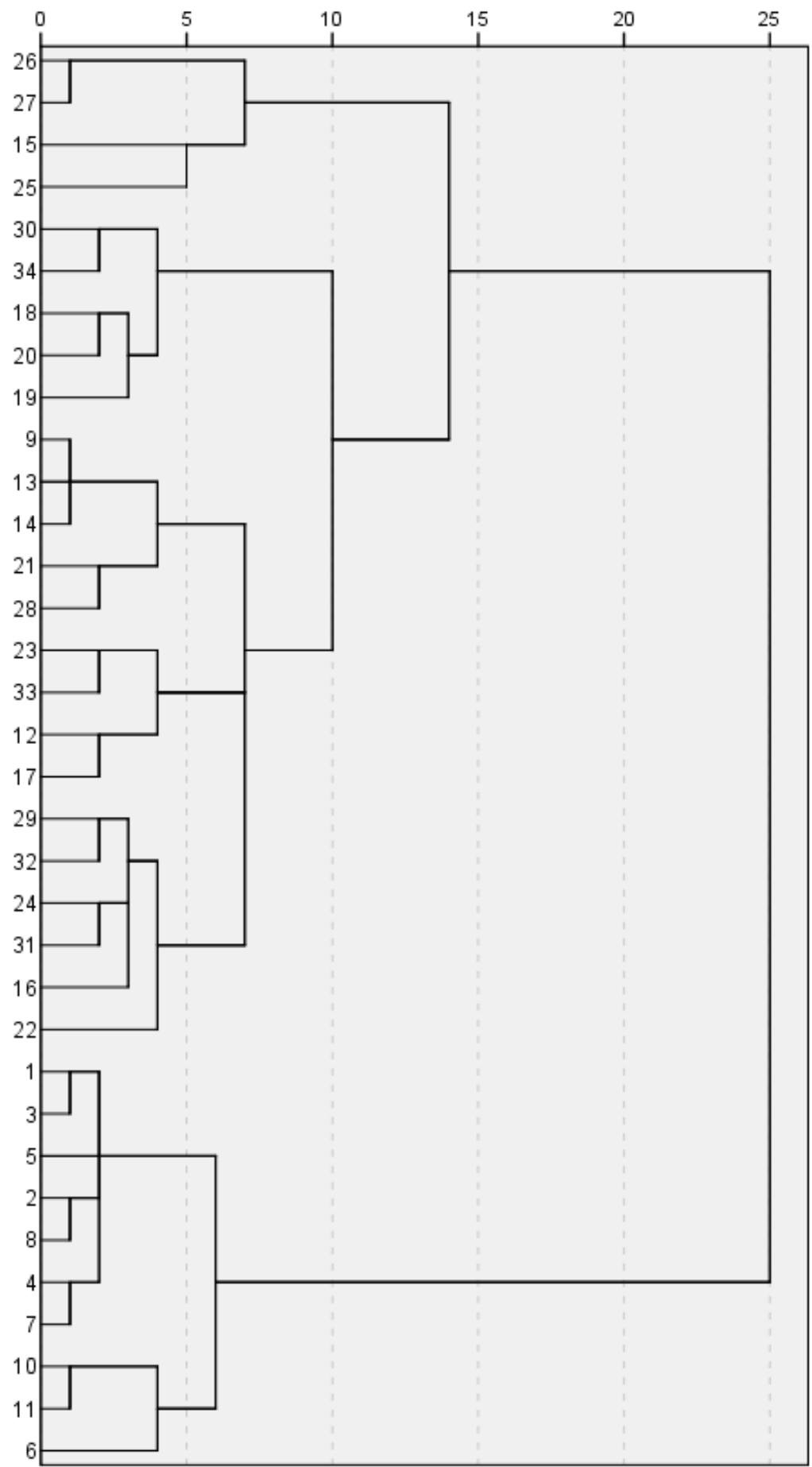

Figura 1. Dendograma de la matriz de distancias biológicas entre diferentes poblaciones mundiales y colombianas, obtenido a partir de la frecuencia de siete de los RMDC tenidos en cuenta en este estudio (incisivos en pala, cúspide Carabelli, patrón cuspídeo, pliegue acodado, protostílido, cúspide 6 y cúspide 7$)$. 
Respecto a la correspondencia entre la expresión y la variabilidad de un mismo RMDC en dos tipos de dientes de una misma clase de toda la muestra, se encontró que hubo correlación para las expresiones en fosa de la cúspide Carabelli entre molares temporales y permanentes y entre molares permanentes, considerada prácticamente ausente del total de la muestra. También se encontró correlación para la ausencia de reducción del hipocono en los primeros y segundos molares permanentes, para la tendencia a configurar cinco cúspides en los molares temporales y permanentes, para la cúspide 6 entre los molares deciduos y permanentes y entre los primeros y segundos molares permanentes, y para la ausencia de la cúspide 7 entre molares temporales y permanentes. Para el resto de RMDC no hubo correlación asociada a la gran variabilidad de los grados de expresión que condiciona la dicotomía presencia/ausencia (Tabla 4).

Tabla 4. Correspondencia entre RMDC de dos tipos de dientes de una misma clase de dientes de toda la muestra

\begin{tabular}{|l|c|c|}
\hline \multicolumn{1}{|c|}{ Rasgo } & Dientes & ${\text { Correlación }(\mathrm{p}<0,05)^{\mathrm{a}}}$ \\
\hline Winging- Crowding & UI1/U12 & 0,948 \\
\hline Forma de pala & UI1/UI2 & 0,133 \\
\hline Forma de pala & UI1/U12 & 0,164 \\
\hline Doble pala & UI1/UI2 & 0,871 \\
\hline Doble pala & UI1/UI2 & 0,942 \\
\hline Cúspide de Carabelli & um1/UM1 & 0,008 \\
\hline Cúspide de Carabelli & UM1/UM2 & 0,367 \\
\hline Reducción del hipocono & UM1/UM2 & 0,007 \\
\hline Protostílido & lm1/LM1 & 0,405 \\
\hline Protostílido & LM1/LM2 & 0,160 \\
\hline Pliegue acodado & lm1/LM1 & 0,149 \\
\hline Pliegue acodado & LM1/LM2 & 0,785 \\
\hline Patrón cuspídeo & lm1/LM1 & 0,157 \\
\hline Patrón cuspídeo & LM1/LM2 & 0,012 \\
\hline Número de cúspides & lm1/LM1 & 0,016 \\
\hline Número de cúspides & LM1/LM2 & 0,017 \\
\hline Cúspide 6 & lm1/LM1 & 0,011 \\
\hline Cúspide 6 & LM1/LM2 & 0,024 \\
\hline Cúspide 7 & lm1/LM1 & 0,038 \\
\hline Cúspide 7 & LM1/LM2 & 0,837 \\
\hline
\end{tabular}

a. Prueba de Wilcoxon

Finalmente, se encontró una tendencia de herencia de la expresión dicotómica presencia/ausencia de los RMDC desde las madres hacia los hijos - evidenciado en que la madre y el hijo se encontraron asociados en el tercer y cuarto cuadrante (Figura 2 y 3 ) - para la presencia de forma de pala en los incisivos centrales superiores permanentes, para la presencia de doble pala en los incisivos laterales superiores permanentes, para la ausencia de cúspide de Carabelli en los primeros molares superiores permanentes, para la ausencia de expresiones cuspídeas del protostílido en los primeros molares inferiores permanentes, para un número mayor de 5 cúspides en los primeros molares inferiores permanentes, y para la presencia de la cúspide 6 en los primeros molares inferiores permanentes. 


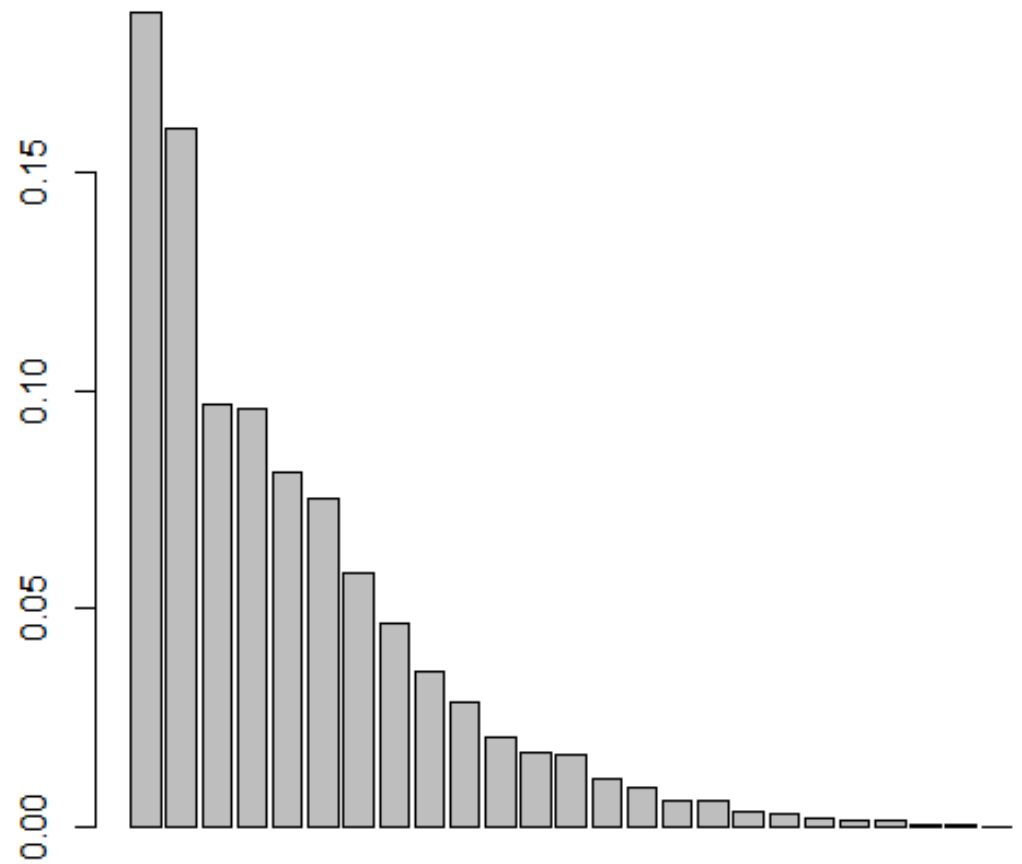

Figura 2. Distribución de la inercia en ejes factoriales a partir de un análisis de correspondencia múltiple desde la expresión dicotómica presencia/ausencia de los RMDC tenidos en cuenta en este estudio para ambas denticiones.

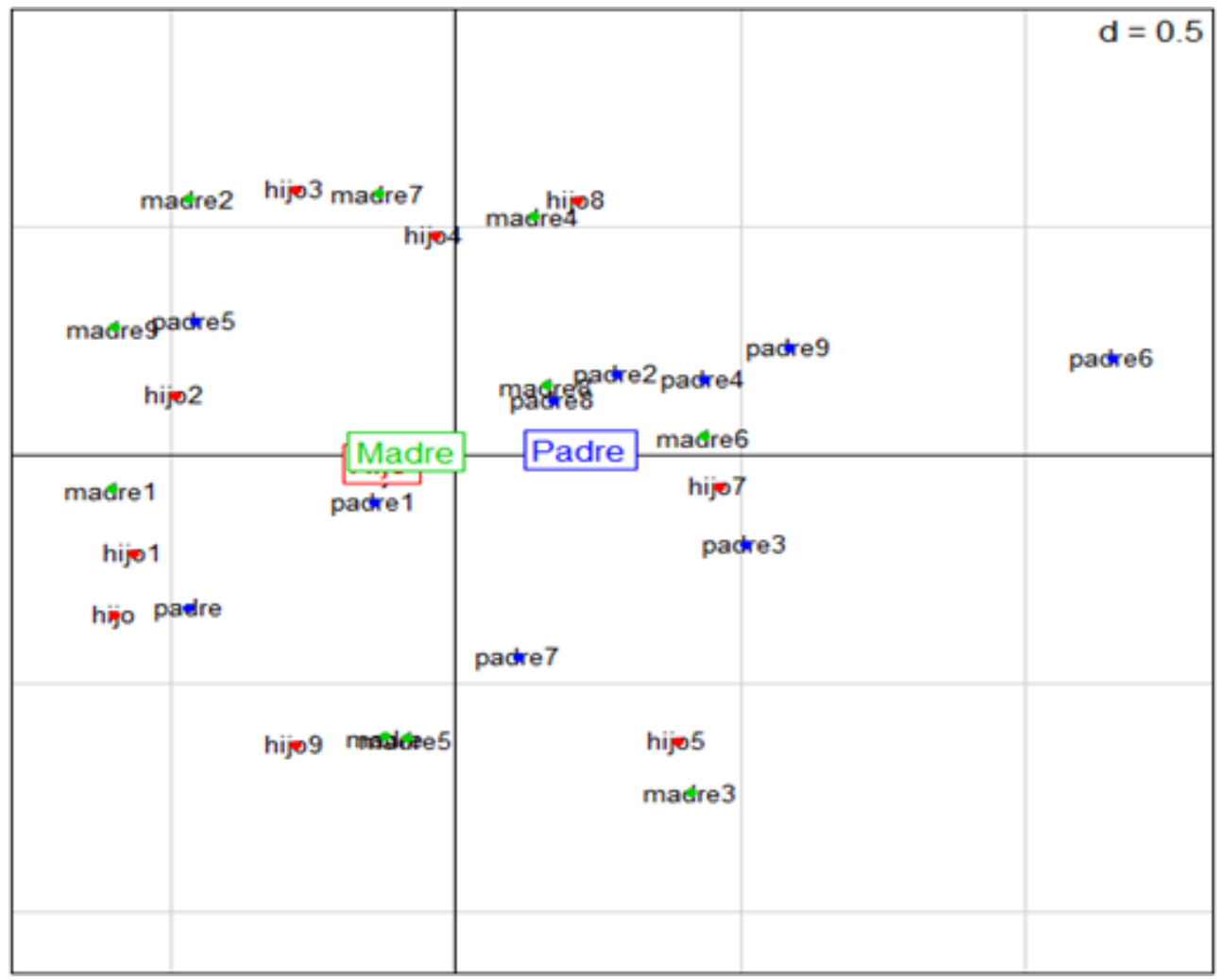

Figura 3. Distribución de los individuos de las diez familias en los cuatro cuadrantes. Se puede observar la inercia de aproximación entre hijos y madres en el tercer y cuarto cuadrantes. 


\section{Discusión}

De forma general, la frecuencia y la variabilidad de los RMDC tenidos en cuenta en este estudio se comportaron de una manera muy similar a lo reportado en estudios previos en población misak (Gutiérrez, Revelo, Burgos, Zambrano, Cerón y Tello, 2017). No obstante, la discusión se realizará inicialmente por clase de dientes y la expresión de los RMDC respectivos, y posteriormente de acuerdo como el modo de herencia de los mismos rasgos morfológicos.

En los incisivos centrales y laterales superiores permanentes, y para el caso del crowding y del winging (dos rasgos que hacen referencia a la posición que ocupan los incisivos superiores en el arco dental maxilar), se observó la tendencia a la expresión de la migración vestibular o palatina de los incisivos laterales respecto a los centrales, y la rotación de la superficie distal de estos hacia vestibular respecto a la línea media — configurando una "V" . Este patrón de apiñamiento de los dientes anteriores superiores ha sido descrito como una característica distintiva de las poblaciones indígenas colombianas pasadas y presentes, asociada fundamentalmente a su origen mongoloide (específicamente del complejo dental sinodonte) (Rodríguez, 2003), o como es el caso de algunas poblaciones de mestizos caucasoides y afrodescendientes, al mestizaje con poblaciones indígenas con quienes han establecido contacto (Moreno y Moreno, 2016). De igual forma, algunos estudios han asociado este tipo de apiñamiento dental al aumento del volumen de la corona de los dientes anteriores superiores por la expresión de la forma de pala y doble pala (Dahlberg, 1963), representadas, respectivamente, por una fosa palatina relativamente profunda, circunscrita por crestas marginales medianamente marcadas (grado 3) y una concavidad de la superficie vestibular asociada a la expresión en trazo (grado 2) del reborde marginal distal, mucho más evidente en los incisivos laterales.

Los molares superiores deciduos y permanentes se caracterizaron por presentar expresiones en fosa de la cúspide de Carabelli (grados 1 y 2), lo que ocasiona que este rasgo morfológico se considere prácticamente ausente en la muestra, tal y como ocurre en poblaciones incluidas en el complejo dental mongoloide (Turner II, 1984; Hanihara, 1992); o como es el caso de las poblaciones indígenas del suroccidente colombiano, con baja influencia de los complejos dentales caucasoide y negroide (Irish, 1998; Edgar, 2007).

Por otro lado, un hallazgo fundamental es la ausencia de reducción del hipocono entre los primeros y los segundos molares superiores permanentes, lo que implica que la cúspide disopalatina tiende a mantener su tamaño (grados 0 y 1), característica de las poblaciones indígenas americanas (Zoubov, 1998; Rodríguez, 2003).

Los RMDC de los molares inferiores decíduos y permanentes se caracterizaron por configurar una superficie oclusal típica de poblaciones modernas con notable influencia mongoloide, como lo son el pliegue acodado, el patrón cuspídeo Y5 molar de cinco cúspides) y Y6 (molar con seis cúspides — presencia relativamente baja de la cúspide 6 o la cúspide 7-). Cabe destacar la alta frecuencia del punto $\mathrm{P}$ (fosita vestibular) del protostílido, cuya expresión ha sido descrita como una característica propia de las poblaciones indígenas pasadas y presentes. 
Finalmente, al analizar la correspondencia de los RMDC, fueron significativas las expresiones -entre los segundos molares decíduos y los primeros molares permanentes del pliegue acodado, del punto $\mathrm{P}$ protostílido, del patrón cuspídeo en $\mathrm{Y}$, del número cinco de cúspides y de la cúspide 7. Para ello se empleó escala de conversiones propuesta por Edgar y Lease (2007), debido a que los métodos de observación de los RMDC utilizan escalas de observación diferentes.

Ocampo, Sánchez, Martínez y Moreno (2009) habían realizado un estudio de correspondencia de algunos RMDC en tres grupos étnicos colombianos (mestizos caucasoides, afrodescendientes e indígenas del Amazonas) en el que no encontraron resultados significativos, debido a la amplia variabilidad de la expresión asociada al mestizaje. Sin embargo, dada la correspondencia estadísticamente significativa de este estudio, se apoya lo propuesto por Buttler (1939) y posteriormente modificado por Dahlberg (1945) a través de la teoría de los campos morfogenéticos, en donde los segundos molares permanentes se constituyen en el diente gradiente de la clase molar, de tal forma que expresión discreta (presencia/ausencia) y variabilidad (gradación) de los mismos se debería conservar en el primer molar permanente, y debido al probable efecto mutacional, epigenético o medio ambiental, ir simplificando sus estructuras hacia el tercer molar (Townsend, Harris, Lesot, Clauss y Brook, 2009).

Con todo ello, se puede afirmar que la muestra misak de este estudio corresponde a un grupo étnico relativamente aislado que ha sufrido muy poca influencia del mestizaje con poblaciones mestizas y afrodescendientes, con las cuales ha compartido el territorio geográfico (García, Gustín, Quiñonez, Sacanamboy, Torres, Triana, Valencia, Rojas, Gómez, Díaz, Sánchez y Moreno, 2015; Gutiérrez, Revelo, Burgos, Zambrano, Cerón y Tello, 2017; García, Gustín, Quiñonez, Sacanamboy, Torres, Triana, Rojas, Gómez, Díaz y Moreno, 2018), asociado fundamentalmente a una serie de consideraciones étnicas como su sentido de pertenencia milenario, e históricas como la lucha constante por mantener su territorio ancestral (Pachón, 1996).

\section{Modo de herencia}

En Colombia, los estudios en antropología dental — desde sus inicios a finales del siglo XX (Moreno, González y Rojas, 2019) — sobre la caracterización de la morfología dental de las poblaciones con base en la distribución geográfica y en el patrón étnico, se han centrado en el individuo y en la manera como el genoma a partir del fenotipo contribuye con la expresión y la variabilidad de los RMDC. En un inicio, incluso antes de entender el carácter aditivo de la expresión génica y sus efectos en la variación fenotípica (tras el desarrollo de técnicas genéticas contemporáneas), la atención se centró en los integrantes de la familia como objeto de estudio de los modos de herencia, debido principalmente a que el fenotipo solo varía desde la genética, considerando que la epigenética (ADN no nuclear) y el medio ambiente tienen el potencial de influir en la morfología y las dimensiones de los dientes, por lo que la herencia podría aumentar de forma relativa si la variación genética aumenta, o podría disminuir si la presión de los factores medio ambientales disminuye, haciendo que los individuos presenten una mayor variación fenotípica (Hugjes y Townsend, 2013a, 2013b).

Dentro de los factores genéticos que pueden variar, se ha identificado que muchos de los genes que participan durante las relaciones recíprocas epitelio-mesenquimáticas de la 
odontogénesis, involucran las vías de señalización Fgf, Bmp, Shh, Wnt y Tnf relacionadas con comunicación celular (Thesleff, 2006). Sin embargo, no solo los cambios en el ADN pueden causar variaciones en el fenotipo; también se han detectado diversos factores epigenéticos o cambios en los mecanismos de regulación de la transcripción génica (p. e. los micro-ARN) durante el desarrollo pre y postnatal de los dientes, como respuesta a los procesos de adaptación del genoma ante la presión de factores ambientales. Un ejemplo de ello es el papel de los genes homeobox durante la morfogénesis de los patrones morfológicos de las coronas de las cuatro clases de dientes. Así, variaciones epigenéticas menores de los genes Hox pueden ocasionar divergencia genotípica por variaciones fenotípicas en la expresión de los RMDC, tal como lo han demostrado los estudios de variabilidad de la morfología de la corona dental en gemelos monocigóticos (Hugjes y Townsend, 2013a, 2013b).

Los diferentes reportes sobre correspondencia de la expresión de RMDC entre el segundo molar deciduo y el primer molar permanente, incluido este estudio, han respaldado la teoría de los campos morfogenéticos de Butler, además de la transmisión significativa de la varibilidad genética desde el diente gradiente. Por ello, se ha estimado que la cúspide Carabelli presenta un modo de herencia del $74 \%$ en el segundo molar deciduo y del $81 \%$ en el primer molar inferior permanente, de tal forma que la correlación genética entre ambos dientes fue de 0,42. Esto indica un grado moderado de independencia —o lo que es lo mismo, una fuerte contribución genética- en los genes que regulan la expresión de este rasgo morfológico en ambas denticiones. En el caso de este estudio, hubo correspondencia entre la ausencia del rasgo (grado 0) y las expresiones fosa (grados 1 y 2), propia de las poblaciones que han recibido fuerte influencia del complejo dental mongoloide. En el caso de la expresión de las cúspides 6 y 7, la estimación del modo de herencia varió del $77 \%$ al $99 \%$ desde el segundo molar inferior deciduo al primer molar inferior permanente. En este estudio, la correspondencia de estas cúspides giró en torno a la expresión de cúspides pequeñas (Grados 2 y 3). Finalmente, la reducción del tamaño de la cúspide distopalatina desde primer molar superior permanente hacia el segundo refleja un fuerte control genético cuya variación fenotípica puede ser suceptible a efectos genéticos aditivos, dado que la tendencia en las poblaciones indígenas americanas - derivadas del complejo dental mongoloide - es hacia la reducción de esta cúspide, denominada en el contexto antropológico como hipocono. Así, la reducción del hipocono fue alta en la muestra de este estudio (Hugjes y Townsend, 2013a, 2013b; Alvesalo, 2013).

En este sentido, se pudo evidenciar que hay una tendencia hacia la herencia de la expresión dicotómica presencia/ausencia de los RMDC — al interior de cada familia - desde la madre hacia el hijo, fundamentalmente para la presencia en grado 3 y grado 2 en la expresión de la forma de pala y doble pala respectivamente; para la ausencia en grado 0 y grado 1 en la expresión de la cúspide de Carabelli; para la ausencia en grado 0 en la expresión del protostílido; para un número mayor de cinco cúspides representado en las expresiones en grados 2, 3 y 5 de la cúspide 6. Llama la atención el caso de la expresión del crowding, cuya expresión dicotómica en los hijos fue del $50 \%$, siendo ausente en las madres y presente en los padres, de tal forma que no hubo influencia hereditaria (al ser un rasgo con baja varianza genética) para el desarrollo del apiñamiento de los incisivos laterales superiores permanentes. Por tanto, su expresión en los grados 1 y 2 puede ser asociado al medio ambiente. Por otro lado, un hallazgo fundamental fue la ausencia de reducción del hipocono entre los primeros 
y segundos molares superiores permanentes, lo que implica que la cúspide disopalatina tiende a mantener su tamaño (grados 0 y 1), comportamiento que se observó en los tres integrantes de cada familia.

\section{Conclusiones}

La discusión en esta investigación se basó en descripciones estadísticas a partir de la expresión fenotípica de los RMDC, los cuales fueron estudiados de acuerdo con los sistemas de observación, registro y análisis reportados en la literatura, y contrastados con los hallazgos de los estudios en gemelos monocigóticos. No obstante, los resultados deben ser interpretados con discreción, debido al tamaño de la muestra.

En términos generales, se encontró una tendencia de herencia de la expresión dicotómica presencia/ausencia de los RMDC desde la madre hacia el hijo para la forma de pala, doble pala, cúspide de Carabelli, número de cúspides y cúspide 6. Para el caso del crowding, la presencia en la madre y la ausencia en el padre no influye en la expresión en el hijo. Para la reducción del hipocono, la ausencia fue evidente en los tres integrantes de cada una de las familias. La expresión del resto de rasgos morfológicos (winging, patrón cuspídeo, protostílido y cúspide 7) no presentó ninguna tendencia hacia la madre o el padre. La ausencia de dimorfismo sexual y la simetría bilateral, además de la correspondencia de algunos rasgos entre la dentición decidua y permanente, evidencia un fuerte control genético en el modo de herencia de la expresión y una baja influencia del medio ambiente, lo que soporta el modelo de campos morfogenéticos propuesto por Butler y modificado por Dahlberg.

La expresión (presencia/ausencia) y la variabilidad (gradación) de los RMDC estudiados demuestran que el grupo de indígenas misak corresponde a una población con alta influencia del complejo dental mongoloide y baja influencia de los complejos dentales caucasoide y negroide (tal y como se pudo evidenciar en el denodograma) - pese a que comparte el territorio geográfico con poblaciones mestizas caucasoides y afrodescendientes-, lo cual puede ser explicado por el sentido de preservación asociado a la pertenencia étnica. De esta forma, la muestra se caracterizó por expresiones significativas del punto $\mathrm{P}$ del protostílido, del pliegue acodado, del patrón cuspídeo en Y5 y de cúspide 6 en los segundos molares deciduos; del crowding, del winging y de la forma de pala de incisivos centrales y laterales superiores permanentes; de reducción de hipocono en los segundos molares superiores permanentes; y del punto $\mathrm{P}$ del protostílido y del patrón cuspídeo Y6 de los primeros y segundos molares inferiores permanentes.

\section{Agradecimientos}

Los autores agradecen al Hospital Mama Dominga del muncipio de Silvia (Cauca, Colombia) por facilitar el acceso a la población para conformar la muestra de este estudio, a través del Programa de Puestos de Salud distribuidos en las veredas del área de influencia. Y por supuesto, agradecemos a las familias misak que con su participación voluntaria y desinteresada contribuyeron con la conformación de la muestra.

\section{Referencias}

Alt, K. W., Rosing, F. W. y Teschler-Nicola, M. (1998). Dental anthropology: Fundamentals, limits, and prospects. New York, Estados Unidos: Springer-Verlag. 
Alvesalo, L. (2013). The expression of human sex chromosome genes in oral and craniofacial growth. En G. R. Scott y J. D. Irish (E), Anthropological perspectives on tooth morphology (pp. 92-107). Cambridge, United Kingdom: Cambridge University Press.

Asociación Médica Mundial. (1964). Principios éticos para las investigaciones médicas en seres humanos, Declaración de Helsinki. Recuperado de http://www.urosario.edu.co/EMCS/Documentos/investigacion/declaracion_helsinki/

Asprilla, P., Franco, K., Morales, J. y Moreno, F. (2017). Caracterización morfológica de la dentición permanente de un grupo de afrodescendientes de Istmina (Chocó, Colombia). Rev. Estomatol, 25(2), 17-24.

Benavides E. A., Coronel, A. y Ruiz, D. V. (2014). Análisis microbiológico de la etnofarmacología empleada por el pueblo Misak. Rev Salud Pública, 16 (4), 610-620.

Bravo, G. E., Buitrago, Y. A. y Zarante, I. (2003). Análisis morfológico dental de dos poblaciones afrocolombianas comparadas con otras poblaciones del mundo. Univ Odontol, 23(52), 21-32.

Brook, A. y Brook-O’Donnell, M. (2013). Modelling the complexity of the dentition. En G. Townsend G, E. Kanazawa and H. Takayama (Ed.), New directions in dental anthropology: Paradigms, methodologies and outcomes (pp. 1-9). Adelaide, Australia: University of Adelaide Press.

Butler, P. M. (1939). Studies of the mammalian dentition. Differentiation of the post-canine dentition. Proc Zool Soc Lond B, 109, 1-36. DOI: https://doi.org/10.1111/j.14697998.1939.tb00021.x

Butler, P. M. (1956). The ontogeny of molar pattern. Biological Reviews, 31(1), 30-69. DOI: https://doi.org/10.1111/j.1469-185X.1956.tb01551.x

Butler, P. M. (1972). Some functional aspects of molar evolution. Evolution, 26(3), 474-83. DOI: https://doi.org/10.1111/j.1558-5646.1972.tb01951.x

Cobourne, M. T. y Mitsiadis, T. (2006). Neural crest cells and patterning of the mammalian dentition. $J$ Exp Zool B Mol Dev Evol, 306(3), 251-60. DOI: https://doi.org/10.1002/jez.b.21084

Dahlberg, A. A. (1945). The changing dentition of man. J Am Dent Assoc, 32, 676-90. DOI: https://doi.org/10.14219/jada.archive.1945.0112

Dahlberg, A. A. (1963). Analysis of the American Indian dentition. En D. R. Brothwell (Ed.), Dental Anthropology (pp. 149-177). London, United Kingdom: Pergamon.

Delgado-Burbano, M. E. (2007). Population affinities of African Colombians to Sub-Saharan Africans based on dental morphology. HOMO, 58, 329-56. DOI: 10.1016/j.jchb.2006.12.002

Departamento Administrativo Nacional de Estadística DANE. (2019). Población indígena de Colombia. Resultados del Censo nacional de población y vivienda 2018. Recuperado de https://www.dane.gov.co/index.php/estadisticas-por-tema/demografiay-poblacion/grupos-etnicos/informacion-tecnica

Díaz, E., García, L., Hernández, M., Palacio, L., Ruiz, D., Velandia, N., Villavicencio, J. y Moreno, F. (2014). Frequency and variability of dental morphology in deciduous and permanent dentition of a Nasa indigenous group in the municipality of Morales, Cauca, Colombia. Colomb Med, 45(1), 15-24.

Edgar, J. H. H. (2007). Microevolution of African American dental morphology. Am J Phys Anthropol, 132, 535-44. DOI: https://doi.org/10.1002/ajpa.20550 
Edgar, H. J. H. y Lease, L. R. (2007). Correlations between deciduous and permanent tooth morphology in a european American sample. Am J Phys Anthropol, 133(1), 726-34. DOI: https://doi.org/10.1002/ajpa.20564

García, A., Gustín, F., Quiñonez, C., Sacanamboy, L., Torres, M. H., Triana, L., Valencia, D., Rojas, E., Gómez, J., Díaz, J., Sánchez, P. y Moreno, F. (2015). Caracterización de 12 rasgos morfológicos dentales en premolares de indígenas Misak de Silvia, Cauca (Colombia). Revista Colombiana de Investigación en Odontología, 6(17), 77-89.

García, A., Gustín, F., Quiñonez, C., Sacanamboy, L., Torres, M. H., Triana, L., Rojas, E., Gómez, J., Díaz, J. y Moreno, F. (2018). Superficie lingual de los caninos deciduos en un grupo de indígenas Misak (Cauca, Colombia): Una mirada desde la antropología dental. Rev Nac Odontol, 14(27), 1-12. DOI: https://doi.org/10.16925/od.v14i27.2340

Grine F. E. (1986). Anthropological aspects of the deciduous teeth of African blacks. En L. Singer y J. K. Lundy (Ed.), Variation, culture, and evolution in African populations (pp. 47-83). Johanessburg, Sudáfrica: Witwatersrand University Press.

Gutiérrez, D. A., Revelo, I. A., Burgos, Y., Zambrano, D., Cerón, E. Y. y Tello, M. F. (2017). Descripción de rasgos morfológicos y métricos dentales en población indígena del Cauca. Cs Morfol, 19(1), 35-41.

Hanihara, K. (1966). Mongoloid dental complex in the deciduous dentition. J Anthrop Soc Nippon, 74(2), 9-20. DOI: https://doi.org/10.1537/ase1911.74.61

Hanihara, T. (1992). Dental and cranial affinities among populations of East Asia and the Pacific: The basic populations in East Asia, IV. Am J Phys Anthropol, 88, 163-82. DOI: https://doi.org/10.1002/ajpa.1330880205

Hugjes, T. E. y Townsend, G. C. (2013a). Genes for teeth: Drawing inference from family data. En G. R. Scott GR y J. D. Irish JD (Ed.), Anthropological perspectives on tooth morphology (pp 22-34). Cambridge, United Kingdom: Cambridge University Press.

Hugjes, T. E. y Townsend, G. C. (2013b). Twin and family studies of human dental crown morphology: genetic, epigenetic, and environmental determinants of the modern human dentition. En G. R Scott GR y J. D. Irish JD (Ed.), Anthropological perspectives on tooth morphology (pp. 31-51). Cambridge, United Kingdom: Cambridge University Press.

Irish, J. D. (1998). Ancestral dental traits in recent Sub-Saharan Africans and the origins of modern humans. HOMO, 34, 81-98. DOI: https://doi.org/10.1006/jhev.1997.0191

Jernvall, J. y Jung, H. S. (2000). Genotype, phenotype, and developmental biology of molar tooth characteristics. Am J Phys Anthropol, Suppl 31, 171-90. DOI: https://doi.org/10.1002/1096-8644(2000)43:31+<171::AID-AJPA6>3.0.CO;2-3

Kraus, B. S. (1952). Morphologic relationships between enamel and dentine surfaces of lower first molar teeth. $J$ Dent Res, 31(2), 248-56. DOI: https://doi.org/10.1177/00220345520310021001

Marcovich, I., Prado, E., Díaz, P., Ortiz, Y., Martínez, C. y Moreno, F. (2012). Análisis de la morfología dental en escolares afro-colombianos de Villarica, Cauca, Colombia. Rev Fac Odont Univ Ant, 24(1), 37-61.

Mayhall, J. T. (2000). Dental morphology: Techniques and strategies. En M. A. Katzenberg y S. R. Saunders (Ed.), Biological anthropology of the human skeleton (pp. 103-134). New York, Estados Unidos: Willey-Liss.

McCollum, M. A. y Sharpe, P. T. (2001). Developmental genetics and early hominid craniodental evolution. Bioessays, 23(6), 481-93. DOI: https://doi.org/10.1002/bies.1068 
Mitsiadis, T. A. y Smith, M. M. (2006). How do genes make teeth to order through development? J Exp Zool B Mol Dev Evol, 306(3), 177-82. DOI: https://doi.org/10.1002/jez.b.21104

Moreno, F., Moreno, S. M., Díaz, C. A., Bustos, E. A. y Rodríguez, J. V. (2004). Prevalencia y variabilidad de ocho rasgos morfológicos dentales en jóvenes de tres colegios de Cali, 2002. Colomb Med, 35 (3-Supl 1), 16-23.

Moreno, S. y Moreno, F. (2007). Importancia clínica de la antropología dental. Rev Estomatol, 15(2 Supl. 1), 42-53.

Moreno, S. y Moreno, F. (2016). Relación entre antropología dental y ortodoncia: Frecuencia y variabilidad de winging y crowding en cinco grupos étnicos del suroccidente colombiano. Revista Científica Sociedad de Ortodoncia, 3(1), 47-57.

Moreno, F., González, G. y Rojas, M. P. (2019). Morfología dental contemporánea. En C. Sanabria (Ed.), Odontología forense: Identificación humana y alteraciones del sistema estomatognático en el contexto forense (pp. 123-172). Bogotá, Colombia: Universidad Antonio Nariño: Bogotá.

Nichol, C. R. y Turner II, C. G. (1986). Intra and interobserver concordance in classifying dental morphology. Am J Phys Anthropol, 69(3), 299-315. DOI: https://doi.org/10.1002/ajpa.1330690303

Ocampo, A. M., Sánchez, J. D., Martínez, C. y Moreno, F. (2009). Correlación de diez rasgos morfológicos dentales coronales entre molares deciduos y permanentes en tres grupos étnicos colombianos. Rev Estomat, 17(2), 7-16.

Osborn, H. F. (1888). The evolution of mammalian molars to and from the tritubercular type. The American Naturalist, 22(264), 1067-79.

Pachón, X. (1996). Los Wampi o la Gente de Guambía. En X. Pachón, D. E. Oliveros y L. E. Wiesner (Ed.), Geografía Humana de Colombia: Región Andina Central Tomo IV Volumen II (pp 4-29). Bogotá, Colombia: Instituto Colombiano de Cultura Hispánica.

Pérez, C., Sánchez, C., Moreno, S. y Moreno, F. (2017). Frecuencia y variabilidad de la morfología dental de molares temporales y permanentes en un grupo de mestizos caucasoides de Popayán (Cauca, Colombia). Rev Estomatol, 25(1), 23-31.

Resolución 008430. Por la cual se establecen las normas científicas, técnicas y administrativas para la investigación en salud. Diario Oficial de la República de Colombia, Bogotá, Colombia, 4 de octubre de 1993.

Reyes, G., Bonomie, J., Guevara, E., Palacios, M., Malgosa, A., Chimenos, E., Jordana, X., García-Sívoli, C. (2010). El sistema dental y su importancia en el estudio de la evolución humana: Revisión bibliográfica. Boletín Antropológico, 28(78), 16-43.

Rocha, L., Rivas, H. y Moreno, F. (2007). Frecuencia y variabilidad de la morfología dental en niños afro-colombianos de una institución educativa de Puerto Tejada, Cauca, Colombia. Colomb Med, 38, 210-21.

Rodríguez, J. V. (2003). Dientes y diversidad humana: Avances de la antropología dental. Bogotá, Colombia: Universidad Nacional de Colombia.

Sciulli, P. W. (1998). Evolution of dentition in prehistoric Ohio valley Native americans: II. Morphology of the deciduous dentition. Am J Phys Anthropol, 106(2), 189-205. DOI: https://doi.org/10.1002/(SICI)1096-8644(199806)106:2<189::AID-AJPA6>3.0.CO;2-L

Scott, G.C. y Turner II, C.G. (1997). The anthropology of modern human teeth: Dental morphology and its variation in recent human populations. Cambridge, United Kingdom: Cambridge University Press. 
Scott, G. C. y Turner II, C. G. (1998). Dental anthropology. Ann Rev Antrophol, 17, 99-126. DOI: https://doi.org/10.1146/annurev.an.17.100188.000531

Thesleff, I. (2006). The genetic basis of tooth development and dental defects. Am J Med Genet A, 140(23), 2530-5. DOI: https://doi.org/10.1002/ajmg.a.31360

Thesleff, I., Vaahtokari, A. y Partanen, A. M. (1995). Regulation of organogenesis. Common molecular mechanisms regulating the development of teeth and other organs. Int J Dev Biol, 39(1), 35-50.

Thesleff, I. y Sahlberg, C. (1996). Growth factors as inductive signals regulating tooth morphogenesis. Semin Cell Dev Biol, 7(2), 185-93. DOI: https://doi.org/10.1006/scdb.1996.0025

Thesleff, I. y Sharpe, P. (1997). Signalling networks regulating dental development. Mech Dev, 67(2), 111-23. DOI: https://doi.org/10.1016/S0925-4773(97)00115-9

Townsend, G.C., Dempsey, P. y Richards, L. (1999). Causal components of dental variation: New approaches using twins. En J. T. Mayhall y T. Heikkinen (Ed.), Proceedings of the 11th international symposium on dental morphology (pp 464- 472). Oulu, Hawai: Oulu University Press.

Townsend, G. C., Harris, E. F., Lesot, H., Clauss, F. y Brook, A. (2009). Morphogenetic fields within the human dentition: A new, clinically relevant synthesis of an old concept. Arch Oral Biol, 54(Suppl 1), 34-44. DOI: https://doi.org/10.1016/j.archoralbio.2008.06.011

Townsend, G. C., Hughes, T., Luciano, M., Bockmann, M. y Brook, A. (2009). Genetic and environmental influences on human dental variation: A critical evaluation of studies involving twins. Arch Oral Biol, 54 Suppl 1, 45-51. DOI: https://doi.org/10.1016/j.archoralbio.2008.06.009

Townsend, G. C., Bockmann, M., Hughes, T. y Brook, A. (2012). Genetic, environmental and epigenetic influences on variation in human tooth number, size and shape. Odontology, 100(1), 1-9. DOI: 10.1007/s10266-011-0052-z.

Turner, C. G. (1967). Dental genetics and microevolution in prehistoric and living Koniag Eskimo. J Dent Res, 46(5), 911-7. DOI: https://doi.org/10.1177/00220345670460054901

Turner, C. G. y Hanihara, K. (1977). Aditional features of the Ainu dentition. V. Peopling of the Pacific. Am J Phys Anthropol, 46(1), 13-24. DOI: https://doi.org/10.1002/ajpa.1330460104

Turner II, C. G., Nichol, C.R. y Scott, G. R. (1991). Scoring procedures for key morphological traits of the permanent dentition: The Arizona State University dental anthropology system. En M. A. Nelly y C. S. Larsen (Ed.), Advances in dental anthropology (pp. 13-31). New York, Estados Unidos: Wiley-Liss.

Turner II, C. G. (1984). Advances in the dental search for Native American origins. Acta Anthropogen; 8, 23-78.

Vázquez, B. (2000). Lengua Indígenas de Colombia: Una visión descriptiva. Bogotá, Colombia: Instituto Caro y Cuervo: Bogotá.

Villar, W. y Granobles, A. (2007). Análisis morfológico en población escolar mestiza estrato tres en la ciudad de Cartagena de Indias. Exhumar, 3, 25-30.

Zoubov, A.A (1998). La antropología dental y la práctica forense. Maguaré, 13, 243-52.

Zúñiga, S., Moreno, S. y Moreno, F. (2016). Caracterización morfológica de los segundos molares temporales y los primeros molares permanentes de tres grupos étnicos de la región del Chocó (Colombia). Rev Nac Odontol, 12(22), 43-59. 